\title{
AN IMPROVED TELE-THERMOMETER
}

\section{A. SLOAN, M.B., GH.B., F.F.A.R.C.S.(ENG.), F.R.C.P.(c)}

FOR MANY YEARS induced hypothermia has been used in operating rooms and intensive care units. Recently, however, attention has been drawn to the dangers of the rapid development of hyperpyrexia and the advisability of routine temperature monitoring. ${ }^{1}$ The thermometers previously available either were inadequately

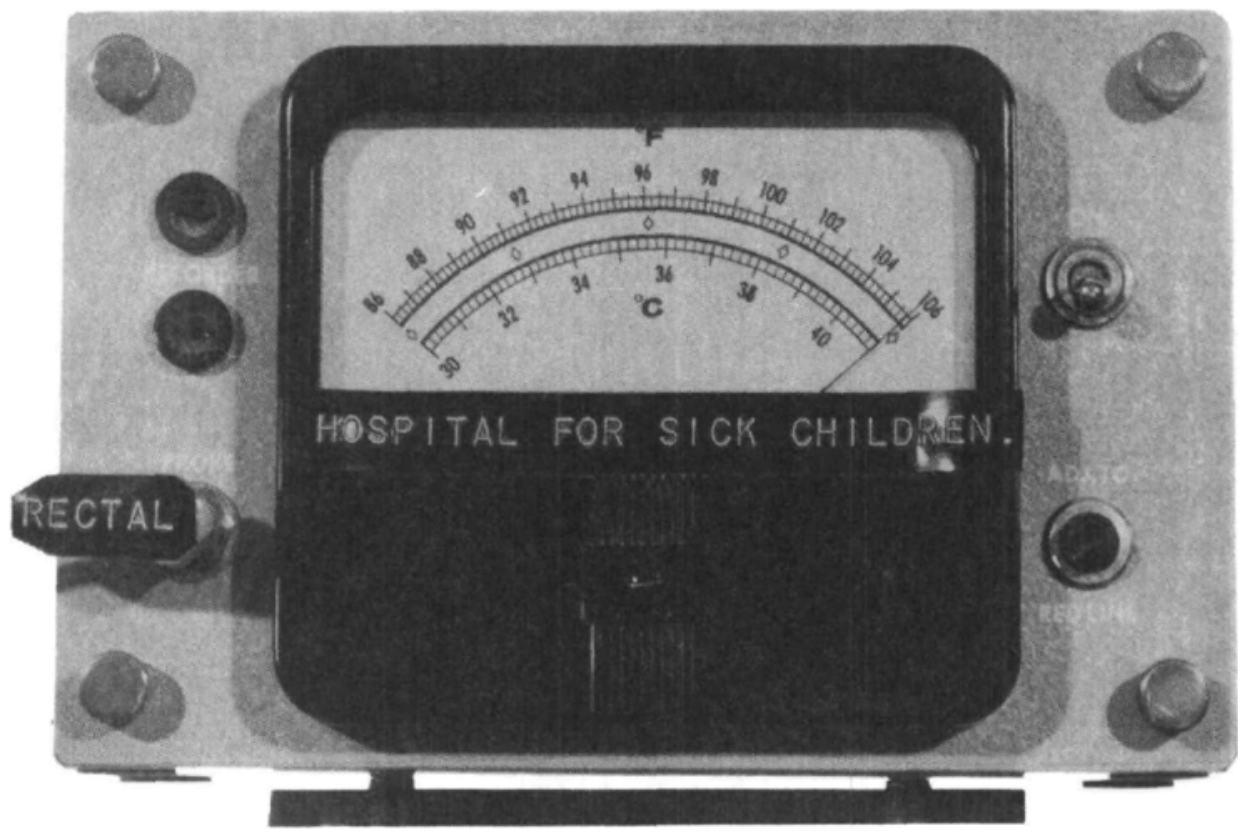

Figure 1

calibrated, or were very sensitive, delicate galvanometers, both unsuitable for routine clinical use.

These problems have been solved by the introduction of a simple, robust, battery-operated tele-thermometer ${ }^{\dagger}$ with a $9 \mathrm{~cm}$. scale covering the clinically useful temperature range $30^{\circ}$ to $41^{\circ} \mathrm{C}$. $\left(86^{\circ}\right.$ to $106^{\circ}$ F.) (Fig. 1$)$. This telethermometer can conveniently be placed on the anaesthetic machine, or anglemounted on an adjustable floor stand, ${ }^{\ddagger}$ as shown in Figure 2.

"Department of Anaesthesia, the Hospital for Sick Children, and University of Toronto. tY. S. I. Tele-thermometer, Hospital for Sick Children model, Canadian Laboratory Supplies, 80 Jutland Road, Toronto 18, Ontario.

¥Adjustable Floorstand \#11242, American Hospital Supply, 1076 Lakeshore Road East, Port Credit, Ontario. 


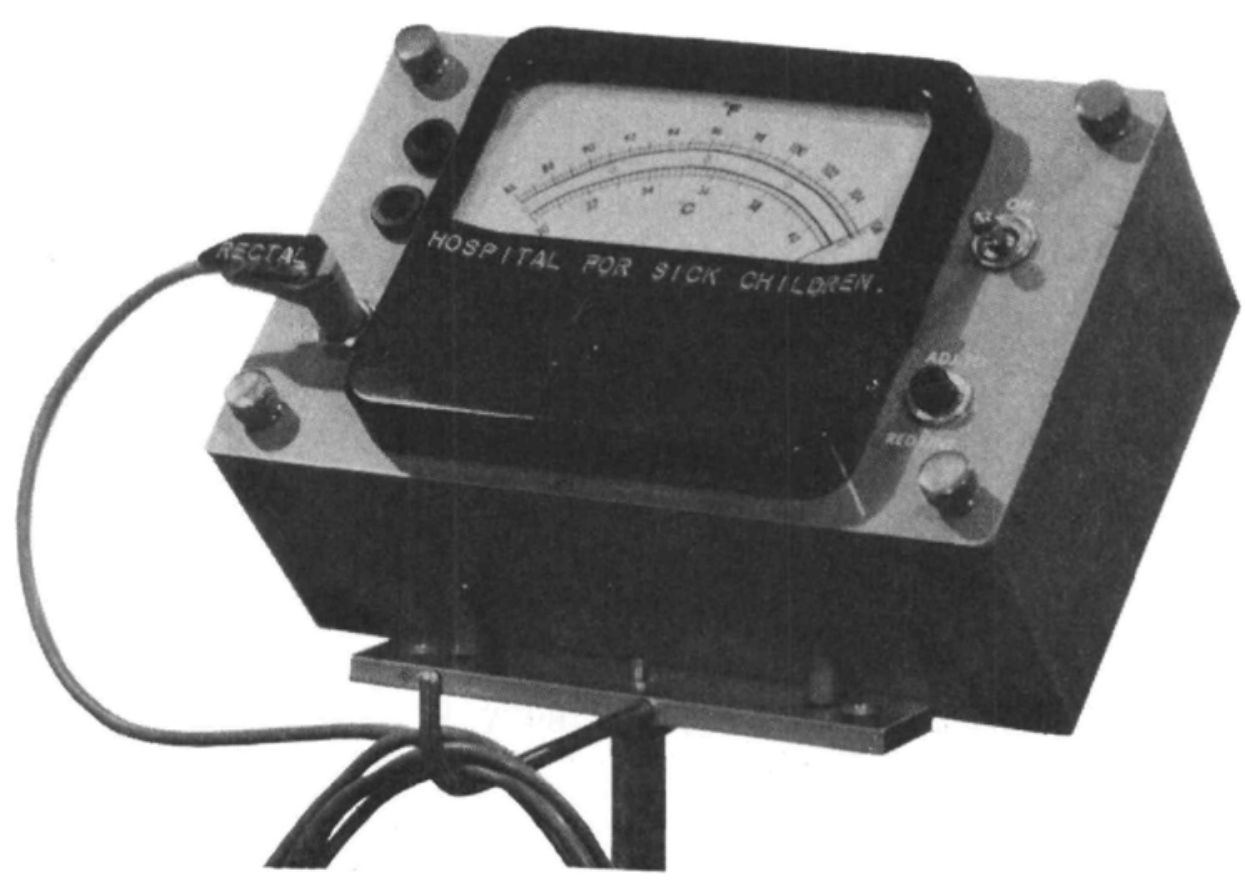

Figure 2

Depuis plusieurs années, on a eu recours à l'hypothermie dans les salles d'opération et dans les unités de soins intensifs. Récemment, toutefois, la littérature a attiré notre attention sur l'apparition rapide de l'hyperpyrexie et sur l'à propos du contrôle routinien de la température. ${ }^{1}$ Les thermomètres à notre disposition antérieurement n'étaient pas convenables pour l'usage clinique de routine car ils n’étaient pas calibrés adéquatement ou ils étaient des galvanomètres très sensibles et très délicats.

Ces problèmes ont été solutionnés par l'apparition d'un télé-thermomètre à batteries, simple, robuste, avec une échelle de $9 \mathrm{~cm}$. couvrant les températures moyennes rencontrées en clinique soit: $30^{\circ}$ à $41^{\circ}$ C. $\left(86^{\circ}\right.$ à $106^{\circ}$ F.) (Fig. 1). Ainsi comme le démontre la Figure 2, ce télé-thermomètre peut être placé sans difficulté sur la machine à anesthésie ou dans un coin sur une tige fixée au sol.

1. Canad. Anaesth. Soc. J. Vol. 13, no. 5 (1966). 